another at angles that never vary for each particular species of crystal. The forms in each set of cases-in organisms and in crystals alike-may be regarded as the necessary resultants of the molecular constitution of their initial units in the particular media and surroundings in which they occur.

\section{PROPERTIES OF ALLOIS.}

THE rescarch described in the report was carried out by the authors with the cooperalion of the Broughton Copper Co., Manchester, and the British Aluminium Co.,

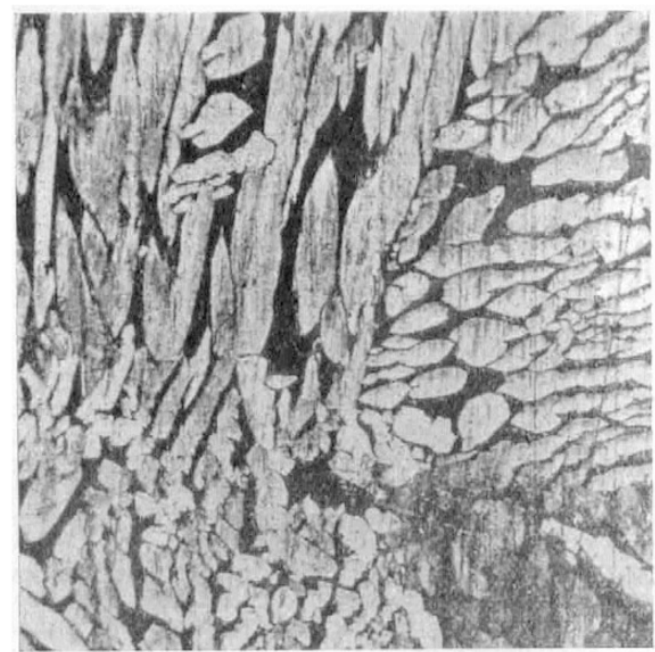

Rolled.

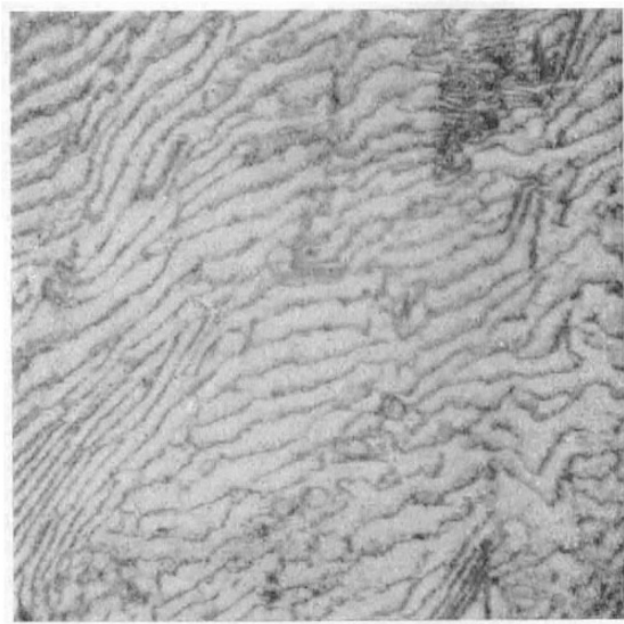

chiefly those very rich in copper. At this end of the series the limit of serviceable alloys must be placed at II per cent. At the other end of the series the limit is cven smaller. Among the specifically light alloys rich in aluminium the limit is probably not higher than 4 per cent. of copper. Belween ir per cent. and 96 per cent. of aluminium (exclusive) the alloys do not appear to be of any practical promise.

(b) But if the range of serviccable alloys is narrow, their quality is cerlainly high in several instances. This statement holds for certain of the rich copper alloys containing between 7 per cent. and so per cent of aluminium. It is not going two far to say that in certain respects the

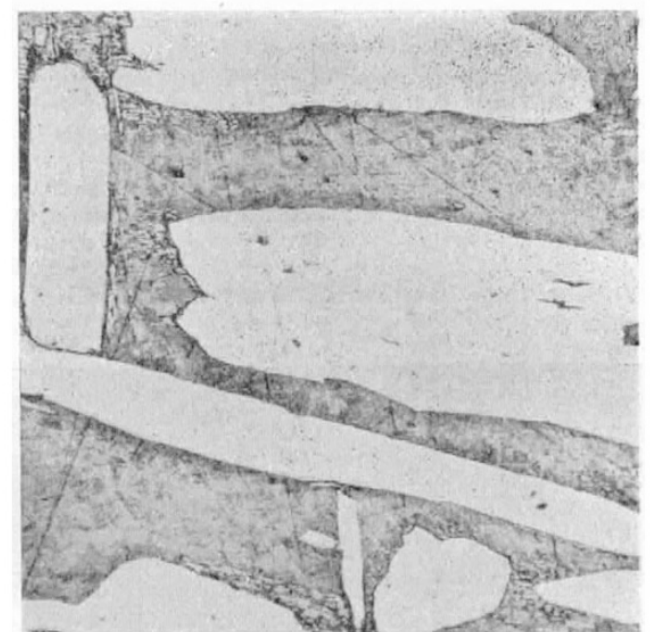

After pr. longed annealing.

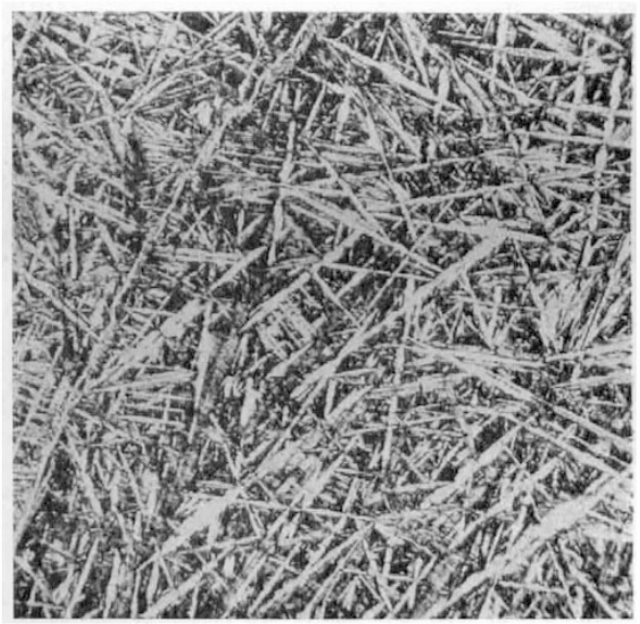

Structures of an alloy cont ining $\left\{\begin{array}{c}90^{\circ} \circ 6 \text { per cent. of copper. } \\ 9.90, " \text { aluminium. }\end{array}\right.$ Magnification I 50 diamet ars."

Milton, who furnished respectively the best commercial copp $\times$ r and aluminium for making the alloys, undertcok the rolling and drawing of the materials, and made special castings where necessary.

The salient points of the report are stated as follows :-

(a) The number of alloys that have been found of any industrial and technical promise is small. Such alloys are

1 Abstract of the Eighth Report to the Alloys Research Committee : On the Properties of Alloys of Aluminium and Copper. By Prof. H. C. H. Car1 inter and Mr. C. A. Edwards, of the National Physical Laboratory. Kead at the Institution of Mechanical Engineers on January 18.

NO. 1948, VOL. 75] best of them equal, and even surpass, high-quality steels of the same general character.

The following summary refers only to the rich copper alloys :-

(c) Four features of the results of the tensile stress tests of outstanding interest merit a special comment.

(I) In view of the doubt which exists at the present time as to whether copper and its alloys possess true yield-points, it is important to record that from o.I per cent. to 9 per cent. of aluminium the alloys possess clearly marked yield-points. 
(2) It has been recently shown by Messrs. Stanton and Bairstow (Proceedings of the Institution of Civil Engineers, I906) that the primitive yield-point of a rolled or forged steel is usually an artificial figure, and is due to a stiffening caused by this mechanical treatment. Such is not the case with these alloys. Their primitive yield-point is the true one.

(3) The ductilities (considered as a product of the percentage elongation and reduction of area) of alloys containing from 0.1 per cent. to 7.35 per cent. of aluminium are very high and practically constant, even although the tenacity increases narkedly with rise of aluminium.

(4) The tenacity and ductility of the widely-known " aluminium bronze" or "gold," containing io per cent. of aluminium, have been found to be as good in the form of small chill castings as in the rolled bar, where an so per cent. reduction of area of the original ingot has been effected. So far as the authors have been able to learn, this result has no parallel. At their request, therefore, independent tests were instituted at the Broughton Copper Works, and these have confirmed the above result, which may have important practical consequences.

(d) The research has brought to light several striking instances of the profound influence of a small quantity of aluminium upon copper, notably in the tension tests, but especially in the torsion and electrical conductivity experiments. One-tenth of $\mathrm{I}$ per cent. raises the angle of twist of copper in torsion 90 per cent.; it lowers the electrical conductivity 23 per cent.

(e) The behaviour in torsional stress of the alloys containing from $0 \cdot x$ per cent. to 7.35 per cent. of aluminium is one of the outstanding features of the report.

$(f)$ The alloys containing from 5 per cent. to ro per cent. of aluminium have come well out of the dynamic stress tests. The particular merit of alloys Nos. 9 and 13 when tested in alternating stress is the close approximation of the maximum stress under which they will bear an unlimited number of reversals to the stress at the elastic limit as determined in a tensile test. In this respect they are markedly superior to the iron and steel specimens hitherto investigated.

Alloys Nos. 6, 9, and 13 stood up well when repeatedly stressed beyond the yield-point in Arnold's test. In fact, Prof. Arnold has informed the authors that "Alloy No. constitutes a record in its capacity of resisting alternations.

(g) At about 15 per cent. of aluminium the alloys are entitled to rank with quenched steels in hardness. Thus the hardness number of No. 17 ( $\times 5.38$ per cent.) in the cast state (untreated) is 539 , which is about that of a 0.45 per cent. carbon steel quenched in water at $20^{\circ} \mathrm{C}$. $\left(68^{\circ} \mathrm{F}.\right)$, and is only slightly lower than that of a 0.66 per cent. carbon steel similarly treated.

(h) In the corrosion tests, which were purposely made as severe as possible, alloys containing from $\mathrm{r}$ per cent. to ro per cent. of aluminium have shown themselves to be practically incorrodible by sea-water, whether alone or bolted to a plate of mild steel. In these tests they showed themselves superior both to Muntz metal and naval brass, which corroded appreciably. In tap water of medium temporary hardness the positions were exactly reversed.

(k) In view of the discussion in the previous report as to the trustworthiness of temperatures measured with a protected thermo-junction, the exact influence of the jacket (a fire-clay tube $1 / 16$ th jnch in thickness) between temperatures of about $1100^{\circ} \mathrm{C}$. and $550^{\circ} \mathrm{C}$. $\left(2012^{\circ} \mathrm{F}\right.$. and $1022^{\circ}$ F.) has been determined. "It has been found to cause a lowering of not more than $3^{\circ} \mathrm{C} .\left(5^{\circ} \cdot 4 \mathrm{~F}\right.$.) at the higher, and $9^{\circ} \mathrm{C} .\left(16^{\circ} \cdot 2^{\circ} \mathrm{F}\right.$.) at the lower temperature, and above $800^{\circ}$ C. $\left(1472^{\circ}\right.$ F.) comes within the experimental errors and uncertainties of the method.

(l) Finally, a special comment must be made on the truly extraordinary similarity in physical and merhanical qualities between alloy No. 13, which consists of 90.06 per cent. of copper +9.90 per cent. of aluminium, and Swedish Bessemer rolled steel of about 0.35 per cent. of carbon and thirty-eight tons per square inch ultimate tensile stress.

NO. I 948 , VOL. 75$]$

\section{A PROPOSED INTERNATIONAL ATTACK ON THE SIDEREAL PROBLEII.}

IN a brochure written by Prof. J. C. Kapteyn, of the Groningen Astronomical Laboratory, the author outlines the chief points of a very comprehensive attack, which he proposes should be made as soon as possible, on the main problems concerning the structure of the sidereal universe.

Whilst the "Carte du Ciel," parts of which are now approaching completion, gives us the relative projecteci positions of all the stars down to the elcventh masnitude and will, by duplication after a number of years, afford material for the accurate determination of proper motions, it leaves untouched the extremely important question as to the distribution of different stellar types in actual space Prof. Kapteyn proposes to supplement this enormous work by the preparalion of a Durchmusterung which shall contain all the necessary data for a preliminary discussion ot the structure of the universe. In fact, he proposes that in the same way that the geological has supplemented the geographical study of the earth, so shall an astrological supplement our astrographical study of the heavens; bu it is obvious that to attempt a scheme like this for th whole of the heavens at once would be to court failure. The plan would probably die of senile decay ere it shower sufficient results to have justified its existence. For thi reason, and acting on the advice of eminent astronomer who favour the idea of such a survey, Prof. Kapteyn limits his proposals to a number of selected areas of the sky. This would reduce the work immensely, and would probably lead to a first approximation of the truths which it is hoped to educe.

The general scheme is based on the method of "gauging " as carried out by the Herschels, only that now, in stead of considering simply the numbers of stars, every ascertainable fact in regard to the objects studied must be considered. The chief data to be obtained, as enumerated by the proposer of the scheme, are visual magnitudes, photographic magnitudes, spectral types, astronomical proper motions, radial velocities, and parallaxes, to which list he adds the determination of the amount of light received from different parts of the sky, as being a subject of great importance to the problem under consideration.

As Prof. Kapteyn points out, there are already sufficient data for the brighter stars, partially excepting parallax and photographic magnitudes, to allow of a fairly thorough statistical treatment, but much of this data needs a great amount of arrangement and classification ere it can be included in a homogeneous attack. The great need in such an inquiry as that proposed is the international study of the fainter stars. Work already completed, or now in hand, will take us down to the seventh or eighth magnitude for most of the elements named, but it is self-evident that, in any attempt to solve the riddle of sidereal struc ture, the Milky Way is an all-important feature, and therefore, far fainter magnitudes than this must be included.

Put into its briefest form, the scope of Prof. Kapteyn's proposals is :--" For 206 areas regularly distributed over the sky, and for another less extensive series of particularly interesting regions, to obtain astronomical data ot every kind for stars down to such faintness as it will be possible to get in a reasonable time." The 206 areas first named come under the designation of "the systematic plan," and are again divided into two classes, the first of which would comprise 118 , and the second eighty-eight areas. These are so arranged that the first class might be completed independently of the second, and would furnish sufficient data for a first approximation. Then, if there were evidence that this could be executed in reasonable time, the second class might be intercalated without interfering with the other, except to provide further data which would, in all probability, enhance the value of the fina! 1906. 